\title{
Research
}

\section{Behavior and health issues in Bengal cats as perceived by their owners: A descriptive study}

\author{
Ana Martos Martinez-Caja ${ }^{\mathrm{a}, *}$, Julie Rosseau ${ }^{\mathrm{a}}$, Hilde Vervaecke ${ }^{\mathrm{b}, 1}$, \\ Christel Palmyre Henri Moons ${ }^{\mathrm{a}, 1}$ \\ ${ }^{a}$ Department of Nutrition, Genetics and Ethology, School of Veterinary Medicine, Ghent University, Merelbeke, Belgium \\ ${ }^{\mathrm{b}}$ Odisee University College, Sint-Niklaas, Belgium
}

\section{A R T I C L E I N F O}

\section{Article history:}

Received 13 September 2019

Received in revised form

23 September 2020

Accepted 7 October 2020

Available online 21 October 2020

\section{Keywords:}

cat welfare

Bengal cat

hybrid breed

cat behavior

\begin{abstract}
A B S T R A C T
The Bengal cat is a recently established hybrid cat breed that was created by crossbreeding the domestic shorthair cat (Felis silvestris catus) and the wild Asian leopard cat (Prionailurus bengalensis). In spite of its popularity, research on behavior and health issues in this breed remains limited. A questionnaire was sent to Bengal cat owners in Flanders and Wallonia (Belgium), and the Netherlands to document the suitability of the breed as a pet from the point of view of the owners by exploring the presence of behavioral and health issues that may provoke the cat's relinquishment. It included questions about their decision to own a Bengal cat, the cat demographics and living environment, potential undesirable behaviors, and health issues. The owners of $60.5 \%(n=155)$ of cats chose this breed due to a combination of looks and character. For most cats $(99.2 \% \mathrm{n}=254)$, the respondents looked for information about the breed before acquiring a cat. Breed-typical health conditions, as described by International Cat Care, were reported in $9.9 \%(\mathrm{n}=24)$ of cats, with being overweight as the most common one. The most frequent behaviors were climbing $(89.5 \%, \mathrm{n}=229)$, vocalizing $(88.7 \%, \mathrm{n}=227)$, playing with water $(79.7 \%, \mathrm{n}=$ $204)$, and hunting $(78.9 \%, n=202)$. These were, however, rarely considered problematic by the owners. The most frequent behaviors often classified as problematic by the owners were destructive behaviors $(33.2 \%, n=85)$, followed by pica $(16.4 \%, n=42)$, aggression toward animals $(16 \%, n=41)$, and urination outside the litter tray $(13.3 \%, \mathrm{n}=34)$. There were no significant differences between cats from early and later generations nor between cats with and without outdoor access. The fact that most owners looked for information about the breed before acquiring the cat and that the most frequently displayed behaviors were not considered problematic by their owners could translate into a lower incidence of relinquishments. Nevertheless, some of those behaviors may still be indicative of welfare issues, independently of the owner's perception. Further and more in-depth research is needed to understand the potential issues of keeping Bengal cats as pets.
\end{abstract}

(c) 2020 Elsevier Inc. All rights reserved.

\section{Introduction}

The Bengal cat is an interspecies hybrid of an Asian leopard cat (Prionailurus bengalensis) and an American or European shorthair cat (Felis silvestris catus) or an Egyptian Mau (Cameron-Beaumont et al., 2002; Vigne et al., 2016; Anonymous, 2017). Asian leopard cats are

\footnotetext{
* Address for reprint requests and correspondence: A. Martos Martinez-Caja, Department of Nutrition, Genetics and Ethology, School of Veterinary Medicine, Ghent University, Heidestraat 19, 9820 Merelbeke, Belgium. Tel: +32 926478 18; Fax: 3292647849.

E-mail address: ana.martos@ugent.be (A. Martos Martinez-Caja).

1 Shared last authorship.
}

believed to be one of the least tameable of all the wild felids, as they do not usually display any social behavior toward their keepers, unlike other felids in captivity (Cameron-Beaumont et al., 2002; Bradshaw et al., 2012a). Consequently, whether domestication traits as those found in domestic cats are also present in Bengal cats is not clear. The proportion of wild felid genes expressed in this breed is difficult to predict, although it is believed to be small (Bradshaw et al., 2012a). The males of the first hybrid generations are sterile, and as a consequence, the fertile hybrid females are crossed with male hybrids from subsequent generations or with male domestic cats (Gershony et al., 2014). The different generations of Bengal cats are identified with an $\mathrm{F}$ (for filial) plus the number of the generation. As such, a Bengal cat originating from a domestic cat and an Asian 
leopard cat would be F1, and an F2 would be the result of crossing an F1 and a domestic cat. It is believed that cats from earlier generations are likely to maintain behavior repertoires closer to those of the Asian leopard cat (Belyaev, 1979; DEWHA, 2008; Vervaecke et al., 2016). However, even if most Bengal cats from later generations have been selected to have a gentle temperament (Cutts, 2008), due to the presumed genetic linkage between the strongly preferred and selected typical wild color patterns and some wild behavior traits (Belyaev, 1979; Kukekova et al., 2011), the small percentage of the leopard cat genes that can be linked to wild behavior are likely to be present in all Bengal cats.

\section{The Bengal cat as a companion animal}

Bengal cats are believed to have some particularities that may affect their relationship with an unprepared owner, such as a more active and/or fearful personality (Salonen et al., 2019). These cats are also reported to display more vocalizations directed to the owner, be more playful (Braastad et al., 2016), show significantly more predatory behavior (Wilhelmy et al., 2016), like to interact with water, often show aggressive behaviors toward members of the family, tend to mark territory and not always use the litter box (Turner and Bateson, 2000).

In addition, some health problems have also been particularly associated with the Bengal breed, such as flat-chested kitten syndrome, progressive retinal atrophy, hip dysplasia, and hypertrophic cardiomyopathy (Vapalahti et al., 2016; International Cat Care, 2017).

Some of the behaviors and health issues mentioned before may be indicative of welfare problems, but there is little research on the welfare of this particular breed, most being limited to the study of heritable health conditions (Bensfield et al., 2011; Ofri et al., 2015; Bourguet et al., 2018).

In addition, little information is known about the environment that Bengal cats are living in when housed as a pet. The living conditions of an animal constitute an important aspect of which types and frequency of behaviors it shows. One of the main environmental factors that influence cats' wellbeing is whether they have access to the outdoors. Outdoor access is believed to be beneficial to cats' welfare, but it also entails some risks such as fights, diseases, accidents, and unwanted pregnancies. Contrarily, cats that are kept indoors may suffer from a lack of stimulation and stress, and frustration due to the impossibility of displaying some natural behaviors (Yeates and Yates, 2017; International Cat Care, 2019). Other factors include the presence of other animals, especially cats, in the same household, the availability of toys, and environmental enrichment. There is no much information available about whether the particularities of the Bengal breed may exacerbate the effect of those factors and contribute to the apparition of potentially undesired behaviors.

An indirect welfare issue may come from the perception of the owners and a mismatch between the Bengal cat behavior and their expectations when acquiring a Bengal cat. The presence of behavioral problems is considered an important reason why people relinquish pets (Patronek et al., 1996; Casey et al., 2009), but also the owners' expectations and knowledge of the normal behavior of cats may influence whether a behavior is perceived as problematic (Scarlett et al., 1999; Stella and Croney, 2016). Pet owners' satisfaction has been reported to be highly related to the chances of relinquishment (Shore, 2005; Marder and Duxbury, 2008; Stella and Croney, 2016).

With the increase in popularity of Bengal cats, the number of cats that have been abandoned in shelters or sanctuaries has increased considerably. For example, in the United States, rescue centers like "Big Cat Rescue" and "Wildcat Sanctuary" have denounced the high amount of requests to take in Bengal cats due to undesirable behaviors such as aggressivity toward people, spraying, or excessive vocalization (Wild Cat Sanctuary, 2012; Big Cat Rescue, 2019).

In this study, we investigate the suitability of Bengal cats as pets based on the behaviors they show and whether their owners find these disturbing. This and the match with the expectations the owners had about Bengal cats provide an indication of how likely owners might be to relinquish their cats, which is considered a potential welfare problem. We map the environment a Bengal cat is typically kept in and whether there is an association with any problematic behavior. We also examine how frequent and which health issues occur. Finally, for behavior, we investigate if (1) cats from early (F1-F4) versus later (F5 and beyond) generations and (2) cats with and without outdoor access differ.

\section{Materials and methods}

An online questionnaire in Dutch and French was made available to owners of Bengal cats in Flanders and Wallonia (Belgium), and in The Netherlands, using the online survey platform www.surveymonkey.com. The questionnaire consisted of 28 multiple choice and openended questions (See annex for an English translation of the questionnaire). Bengal cat owners were invited to complete the survey multiple times if they had more than one Bengal cat in their household. Consequently, the number of responses in the results section reflects the number of Bengal cats, not the number of Bengal cat owners.

\section{Cat demographics and owner expectations}

This part of the questionnaire included questions about the country where the cat resides, the age, generation, sex and reproductive status. It also inquired about the origin of the cat, the reasons behind the choice of the Bengal breed, whether respondents did some research before deciding to acquire the breed, and the sources of information used.

\section{Cat living environment}

For this section, the respondents answered questions about the type of living environment, outdoor access, whether the cats have caused problems in the neighborhood (e.g., by provoking complaints from the neighbors due to urine marking, destruction of property, or aggressivity toward the neighbors or their pets), how long the cat is left alone during the day and the cats' reaction if left alone for long periods of time and the presence of other animals and potential conflicts with those animals.

\section{Behavior, problematic behavior, and behavior problems}

This part included questions about the level of activity and playfulness of the cat. In addition, a list of potentially undesirable behaviors was presented (Table 4). The respondent could indicate if the cats displayed those behaviors and if they were indeed problematic to them or another member of the household (hereafter referred to as "the owners"') or not. This approach is based on Porters et al. (2014) and Moons et al. (2018). The behaviors included in the questionnaire were selected from behaviors that have been commonly associated with Bengal cats in the literature. The list was completed with the addition of some problems (such as fear of people, noises, and objects) that may be presented by cats, independently of their breed, and that are sometimes associated with welfare issues (Bradshaw et al., 1997).

Finally, the respondents were asked whether their cats had been diagnosed with a behavioral problem or if they suspected that their cat had one despite not having been diagnosed. 
Table 1

Information about the acquisition of Bengal cats, expressed as the number and percentage per answer option of cats for which the survey was completed ( $\mathrm{N}=256$ )

\begin{tabular}{|c|c|c|c|}
\hline Category & Sub-category & $\mathrm{n}$ & $\%$ \\
\hline \multirow[t]{3}{*}{ Region } & The Netherlands & 177 & 69.1 \\
\hline & Wallonia & 22 & 8.6 \\
\hline & Flanders & 57 & 22.3 \\
\hline \multirow[t]{2}{*}{ Type of owners } & Cat breeders & 55 & 21.5 \\
\hline & Private owners & 201 & 78.5 \\
\hline \multirow{3}{*}{ Method of obtaining the cat } & Bought from a Bengal cat breeder & 225 & 87.9 \\
\hline & Adopted & 16 & 6.2 \\
\hline & Other & 15 & 5.9 \\
\hline \multirow[t]{6}{*}{ Reasons to choose a Bengal cat } & The looks of the Bengal cat appeals to me & 22 & 8.6 \\
\hline & The character of the Bengal cat appeals to me & 56 & 21.9 \\
\hline & The combination of looks and character appeals to me & 155 & 60.5 \\
\hline & The choice of breed was not important for me & 3 & 1.2 \\
\hline & Someone recommended them to me & 4 & 1.6 \\
\hline & Other & 16 & 6.2 \\
\hline \multirow[t]{5}{*}{ Sources of information pre-acquisition (Multiple answer) } & Internet & 81 & 31.6 \\
\hline & Breeders & 19 & 7.4 \\
\hline & Internet and Breeders & 131 & 51.2 \\
\hline & Other combinations (shows, books, breeder associations, etc.) & 23 & 9.0 \\
\hline & Did not look for information preacquisition & 2 & 0.8 \\
\hline
\end{tabular}

\section{Health problems}

Health data were acquired using the list by International Cat Care of health issues associated with the Bengal breed (International Cat Care, 2017). The health issues were fertility problems, overweight, hip dysplasia, patella luxation, hypertrophic cardiomyopathy, blindness, progressive retinal atrophy, distal neuropathy, and flat chest kitten syndrome. Respondents could also indicate if another health condition had been diagnosed.

\section{Data collection and analysis}

Bengal cat owners (including catteries) were identified and recruited using online search engines and social media. The potential respondents were contacted online, either by private or group messages containing the link to the online survey.

The questionnaire was available during a two-month period at the beginning of 2017. As an exclusion criterion, respondents who did not answer the first eight questions were removed from the analysis. These questions included, among others, the generation, sex, and neuter status of the Bengal cat, as well as reasons for acquiring this particular breed. Responses regarding Asian leopard cats were also excluded since they were not the focus of this study.
An exploratory descriptive analysis was performed using Microsoft Excel 2016 and IBM SPSS statistics 25. Response frequencies (in percentage) for each question were examined, with the total number of responses $(\mathrm{N})$ representing the number of cats for which the question was answered. These percentages are presented in the results section, together with the subtotal (n) of responses corresponding to that answer option.

The potential existence of differences in behavior between cats from earlier (F1-F4) and later generations (F5 and beyond) was investigated to test whether later generations are better adapted to and suited for life as a companion animal. Differences were also explored between cats with and without outdoor access. In both cases, potential differences between the behaviors displayed by the two groups were explored using a Chi-Squared test of goodness-offit with a Bonferroni-adjusted alpha level of $0.003(0.05 / 14)$.

\section{Results}

\section{Cat demographics and owner expectations}

From the 307 responses received, 256 reached the criterion and were included in the analysis. Tables 1 and 2 show the information collected in this part of the questionnaire.

Table 2

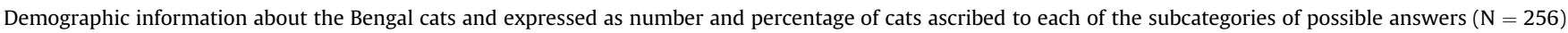

\begin{tabular}{|c|c|c|c|c|c|c|}
\hline Category & 1st subcategory & $\mathrm{n}$ & $\%$ & 2nd subcategory & $\mathrm{n}^{\mathrm{a}}$ & $\%^{\mathrm{a}}$ \\
\hline \multirow[t]{4}{*}{ Reproductive Status } & Female Intact & 40 & 15.6 & & & \\
\hline & Female Neutered & 80 & 31.3 & & & \\
\hline & Male Intact & 20 & 7.8 & & & \\
\hline & Male neutered & 116 & 45.3 & & & \\
\hline \multirow[t]{11}{*}{ Pedigree } & Yes & 226 & 88.3 & & & \\
\hline & No & 30 & 11.7 & & & \\
\hline & $\mathrm{F} 1-\mathrm{F} 4$ & 39 & 15.2 & The Netherlands & 21 & 11.9 \\
\hline & & & & Flanders & 15 & 26.4 \\
\hline & & & & Wallonia & 3 & 13.6 \\
\hline & F5 or later & 108 & 42.2 & The Netherlands & 69 & 39.0 \\
\hline & & & & Flanders & 21 & 36.8 \\
\hline & & & & Wallonia & 18 & 81.8 \\
\hline & Unknown & 109 & 42.6 & The Netherlands & 87 & 49.1 \\
\hline & & & & Flanders & 21 & 36.8 \\
\hline & & & & Wallonia & 1 & 4.6 \\
\hline
\end{tabular}


Table 3

Information about the living environment of Bengal cats, expressed as number and percentage of cats ascribed to each of the subcategories of possible answers

\begin{tabular}{|c|c|c|c|c|c|c|}
\hline Category & 1st subcategory & $\mathrm{n}$ & $\%$ & 2nd subcategory & $\mathrm{n}$ & $\%$ \\
\hline \multirow[t]{2}{*}{ Room access $\mathrm{N}=252$} & All the rooms in the house & 195 & 77.4 & & & \\
\hline & Restricted to one or few rooms & 57 & 22.6 & & & \\
\hline \multirow[t]{12}{*}{ Outdoor access $N=256$} & Indoors only & 150 & 58.6 & Female Intact & 24 & 16.0 \\
\hline & & & & Female Neutered & 41 & 27.3 \\
\hline & & & & Male Intact & 14 & 9.3 \\
\hline & & & & Male neutered & 71 & 47.4 \\
\hline & Outdoors only on leash & 42 & 16.4 & Female Intact & 10 & 23.8 \\
\hline & & & & Female Neutered & 9 & 21.4 \\
\hline & & & & Male Intact & 4 & 9.5 \\
\hline & & & & Male neutered & 19 & 45.3 \\
\hline & Free outdoor access & 64 & 25.0 & Female Intact & 6 & 9.4 \\
\hline & & & & Female Neutered & 30 & 46.9 \\
\hline & & & & Male Intact & 2 & 3.1 \\
\hline & & & & Male neutered & 26 & 40.6 \\
\hline \multirow{4}{*}{$\begin{array}{l}\text { Problems in the neighborhood } \mathrm{N}=64 \\
\quad \text { (Includes only cats with free outdoor access) }\end{array}$} & Never causes any problems & 32 & 50.0 & & & \\
\hline & Rarely causes problems & 8 & 12.5 & & & \\
\hline & Often causes problems & 0 & 0.0 & & & \\
\hline & Unknown/Non applicable & 24 & 37.5 & & & \\
\hline \multirow[t]{3}{*}{ Toy availability $N=249$} & Yes and the cat is interested & 218 & 87.6 & & & \\
\hline & Yes but the cat is not interested & 30 & 12.0 & & & \\
\hline & No & 1 & 0.4 & & & \\
\hline Average daily time of interaction owner-cat (minutes) & \multicolumn{6}{|c|}{ Mean $=97$, median $=60, \mathrm{SD}=93, \min 1.5-\max 700, \mathrm{~N}=239$} \\
\hline
\end{tabular}

Cat living environment

A summary of the information obtained about the cat living environment can be found in Table 3.

\section{Behavior, problematic behavior, and behavior problems}

Regarding the activity level of the Bengal cat, 249 responses were collected. For $34.1 \%(n=85)$ of cats, the respondent described their cat as being frequently very active and playful. For $5.6 \%$ ( $\mathrm{n}=$ 14 ), this was inactive and spending most of the time resting. For the remaining cats, the respondents described their animals as being balanced between active and inactive $(60.3 \%, n=150)$. The percentage of respondents describing their cats as active was slightly lower among the 136 owners that only had Bengal cats $(32.3 \%, \mathrm{n}=$ 44) than among the 120 owners that had both Bengal cats and nonBengal cats $(34.2 \%, \mathrm{n}=41)$. The perception of their cat being particularly active was similar between the 55 cat breeders (34.5\%, $\mathrm{n}=19)$ and the 201 normal cat owners $(32.8 \%, \mathrm{n}=66)$.

Almost half of the cats were left alone for a prolonged period of time (6-8 hours) during weekdays ( $48.4 \%, \mathrm{n}=124)$. According to the respondents, $11.3 \%(n=14)$ of these cats frequently displayed disruptive behavior when they were alone, such as trying to escape from the house or breaking things.

When asked if they would describe their cats as "cats that enjoy close contact" (likes to lie on their lap, likes to be picked up and stroked), $62.5 \%(n=160)$ of all respondents answered positively.

Table 4 shows the percentage of cats that showed each of the proposed behaviors. The percentage of cats that showed at least one behavior considered problematic by the owner was smaller (44.9\%, $\mathrm{n}=115$ ) than the cats that did not show any behavior considered problematic $(55.1 \%, n=141)$. Only $5.1 \%(n=13)$ of the respondents declared that they suspected a behavior problem, and $2.3 \%(n=6)$ said that their cat had actually been diagnosed with a behavior problem. The diagnosed problems described in this section were aggression toward other cats $(n=2)$ and toward humans $(n=1)$, excessive self-grooming $(n=1)$, excessive vocalization $(n=1)$, and inappropriate elimination $(n=1)$. 92.6\% $(n=237)$ of the respondents believed that their cats did not have a behavior problem.

The percentage of Bengal cats that displayed at least one behavior considered to be problematic by their owners was slightly higher in generation $\mathrm{F} 1-\mathrm{F} 4(41.0 \%, \mathrm{n}=16)$ than in generations $\mathrm{F} 5$ or later $(39.8 \%$, $\mathrm{n}=43)$, but the difference was not significant $\left(\chi^{2}(1, \mathrm{n}=155)=0.17\right.$, $P=0.895)$. Regarding the display of each particular behavior, no significant differences were found between the two groups (Table 5). Aggression toward people was only described in cats from F1 to F4, but the percentage was low. The cats whose generation was unknown by the respondent were not included in this analysis.

Regarding the living environment of the cats, the percentage of cats with outdoors access (free or on a leash) that showed at least one undesirable behavior was higher (46.2\%) than the percentage of cats that always remain indoors (44.0\%), but the difference was not significant $\left(\chi^{2}(1, \mathrm{n}=256)=0.124, P=0.724\right)$. For all behaviors examined, there were no significant differences between the two groups (Table 6). Since the number of cats diagnosed with behavioral problems was small, it was not possible to assess the potential effect of the environment on the appearance of these problems.

Most Bengal cats that lived or were frequently in contact with other animals $(84 \%, n=215)$ did not have conflicts with those particular individuals. 9.2\% $(\mathrm{n}=23)$ displayed aggressive behaviors toward familiar animals and 6.0\% $(n=15)$ displayed fear behaviors. A description of the different types of interaction between the cats and the other animals can be found in Table 7.

\section{Health problems}

When asked about health issues, the respondents $(\mathrm{N}=249)$ reported for $78.3 \%(n=195)$ of Bengal cats that they did not show any health problems (Table 8$)$. In contrast, $9.6 \%(n=24)$ of the cats had a health condition that is considered typical for the breed, while $12.1 \%(n=30)$ were reported to suffer from other conditions, with gastrointestinal and autoimmune-related conditions being the most frequent. Only two cats had more than one of the Bengal catrelated conditions. The first one was overweight and had fertility problems, and the second one had blindness and progressive retinal atrophy, although in this last case (a 3-year-old female), both conditions were likely to be related.

\section{Discussion}

The purpose of this research was to investigate the suitability of the Bengal cat as a pet from the point of view of the owners to 
Table 4

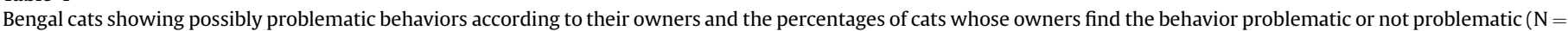
256)

\begin{tabular}{|c|c|c|c|c|c|c|}
\hline \multirow[t]{2}{*}{ Behavior } & \multicolumn{2}{|c|}{$\begin{array}{l}\text { Cats that show this } \\
\text { behavior }\end{array}$} & \multicolumn{2}{|c|}{$\begin{array}{l}\text { Cats whose owners find } \\
\text { this behavior problematic }\end{array}$} & \multicolumn{2}{|c|}{$\begin{array}{l}\text { Cats whose owners do not } \\
\text { find this behavior } \\
\text { problematic }\end{array}$} \\
\hline & $\mathrm{n}$ & $\%$ & $\mathrm{n}$ & $\%$ & $\mathrm{n}$ & $\%$ \\
\hline Climbing & 229 & 89.5 & 3 & 1.3 & 226 & 98.7 \\
\hline Vocalization & 227 & 88.7 & 19 & 8.4 & 208 & 91.6 \\
\hline Hunting behavior & 202 & 78.9 & 2 & 1.0 & 200 & 99.0 \\
\hline Playing with water & 204 & 79.7 & 5 & 2.4 & 199 & 97.6 \\
\hline Excessively licking same spot & 13 & 5.1 & 4 & 30.8 & 9 & 69.2 \\
\hline Destructive behavior & 85 & 33.2 & 42 & 49.4 & 43 & 50.6 \\
\hline Fear response to noises & 83 & 32.4 & 4 & 4.8 & 79 & 95.2 \\
\hline Fear response to people & 43 & 16.8 & 6 & 14.0 & 37 & 86.0 \\
\hline Fear response to some situations & 72 & 28.1 & 6 & 8.3 & 66 & 91.7 \\
\hline Fear response to objects & 46 & 18 & 1 & 2.2 & 45 & 97.8 \\
\hline Aggression toward animals & 41 & 16.0 & 24 & 58.5 & 17 & 41.5 \\
\hline Pica & 42 & 16.4 & 28 & 66.7 & 14 & 33.3 \\
\hline Urine spraying & 37 & 14.5 & 26 & 70.3 & 11 & 29.7 \\
\hline Urination outside the litter tray & 34 & 13.3 & 27 & 79.4 & 7 & 20.6 \\
\hline Aggression toward people & 5 & 2.0 & 4 & 80.0 & 1 & 20.0 \\
\hline
\end{tabular}

indirectly assess the likelihood of relinquishment. This assessment was based on factors that are known to influence the chances of relinquishment, such as behavior, owner expectations, and health issues (Patronek et al., 1996; Salman et al., 2010; Stella and Croney, 2016).

A number of limitations can be identified in this study. First, as with most online questionnaires, the number of questions must be minimized to ensure high participation, thereby limiting the amount of detail that can be collected. We chose to adopt the approach used by Porters et al. (2014) and Moons et al. (2018), where a description of potentially disturbing behaviors is given, along with the question of whether they occurred and if they were disturbing to the respondent or his/her family members. The point of view of the owner is likely to have an impact on the welfare of the cat since owner perception, and satisfaction with their companion animals is an important factor influencing the chances of animal relinquishment (Shore, 2005). Second, in hindsight, some questions may have been interpreted differently than we intended. For instance, the question regarding the amount of time that the respondents actively spend with their cat (Question N. 21). The fact that some owners indicated 12 hours suggests that they interpreted this question as being with the cat rather than spending time interacting with the cat. Also, asking whether the cat had been diagnosed with a behavioral problem but not specifying who should have made the diagnosis makes the interpretation of the positive answers ambiguous. Third, some of the participants in the study were cat owners, while others were also Bengal cat breeders. This could influence the results of the questionnaire, either because the population of cats may be different between breeders and nonbreeders (i.e., due to differences in the numbers of neutered versus intact cats or differences in the living environment (Ström Holst and Frössling, 2009), or because breeders have a different perception of the cats compared to nonbreeders. A final encountered issue was the under-representation of early generation Bengalcats, especially from the Wallonia region in Belgium, but the otherwise high participation suggests that the study provides a good insight on the living situation of the Bengal cats from the Netherlands, Flanders, and Wallonia

Table 5

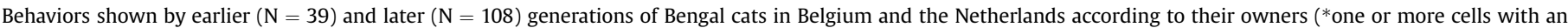
expected count lower than 5)

\begin{tabular}{|c|c|c|c|c|c|c|}
\hline \multirow[t]{2}{*}{ Behavior } & \multicolumn{2}{|c|}{$\begin{array}{l}\text { Early generation cats } \\
\text { (F1-F4) that show this } \\
\text { behavior }\end{array}$} & \multicolumn{2}{|c|}{$\begin{array}{l}\text { Later generation cats (F5 } \\
\text { or further) that show this } \\
\text { behavior }\end{array}$} & \multirow[t]{2}{*}{$\chi^{2}$} & \multirow[t]{2}{*}{$P$} \\
\hline & $\mathrm{n}$ & $(\%)$ & $\mathrm{n}$ & $(\%)$ & & \\
\hline Climbing & 35 & 89.7 & 100 & 92.6 & $\mathrm{n} / \mathrm{a}^{*}$ & $\mathrm{n} / \mathrm{a}^{*}$ \\
\hline Vocalization & 33 & 84.6 & 96 & 88.9 & 0.487 & 0.569 \\
\hline Hunting behavior & 32 & 82.0 & 87 & 80.5 & 0.042 & 0.838 \\
\hline Playing with water & 32 & 82.0 & 89 & 82.4 & 0.002 & 0.962 \\
\hline Excessively licking same spot & 2 & 5.1 & 9 & 8.3 & 0.425 & 0.514 \\
\hline Destructive behavior & 10 & 25.6 & 26 & 24.1 & 0.038 & 0.845 \\
\hline Fear response to noises & 16 & 41.0 & 35 & 32.4 & 0.939 & 0.433 \\
\hline Fear response to people & 8 & 20.5 & 18 & 16.7 & 0.291 & 0.627 \\
\hline Fear response to some situations & 10 & 25.6 & 32 & 29.6 & 0.223 & 0.685 \\
\hline Fear response to objects & 6 & 15.4 & 17 & 15.7 & 0.003 & 0.958 \\
\hline Aggression toward animals & 8 & 20.5 & 14 & 13.0 & 1.283 & 0.297 \\
\hline Pica & 4 & 10.3 & 16 & 14.8 & 0.507 & 0.593 \\
\hline Urine spraying & 5 & 12.8 & 21 & 19.4 & 0.864 & 0.465 \\
\hline Urination outside the litter tray & 5 & 12.8 & 17 & 15.7 & 0.192 & 0.797 \\
\hline Aggression toward people & 2 & 5.1 & 0 & 0.0 & $\mathrm{n} / \mathrm{a}^{*}$ & $\mathrm{n} / \mathrm{a}^{*}$ \\
\hline
\end{tabular}

Cats whose generation was unknown were excluded from this analysis. Bonferroni-corrected alpha-level: 0.003 . 
Table 6

Behaviors shown by Bengal cats with $(\mathrm{N}=106)$ and without $(\mathrm{N}=150)$ outdoor access in Belgium and the Netherlands according to their owners (*one or more cells with an expected count lower than 5)

\begin{tabular}{|c|c|c|c|c|c|c|}
\hline \multirow[t]{2}{*}{ Behavior } & \multicolumn{2}{|c|}{$\begin{array}{l}\text { Cats } \\
\text { without } \\
\text { outdoor } \\
\text { access that } \\
\text { show this } \\
\text { behavior }\end{array}$} & \multicolumn{2}{|c|}{$\begin{array}{l}\text { Cats with } \\
\text { outdoor } \\
\text { access } \\
\text { that show } \\
\text { this } \\
\text { behavior }\end{array}$} & \multirow[t]{2}{*}{$\mathrm{X}^{2}$} & \multirow[t]{2}{*}{$P$} \\
\hline & $\mathrm{n}$ & $(\%)$ & $\mathrm{n}$ & $(\%)$ & & \\
\hline Climbing & 134 & 89.3 & 95 & 89.6 & 0.006 & 0.941 \\
\hline Vocalization & 130 & 86.7 & 97 & 91.5 & 1.450 & 0.229 \\
\hline Hunting behavior & 115 & 76.7 & 87 & 82.1 & 1.092 & 0.296 \\
\hline Playing with water & 118 & 78.7 & 86 & 81.1 & 1.29 & 0.359 \\
\hline Excessively licking same spot & 12 & 8.0 & 1 & 0.9 & 6.416 & 0.011 \\
\hline Destructive behavior & 56 & 37.3 & 29 & 27.4 & 0.008 & 0.928 \\
\hline Fear response to noises & 51 & 34.0 & 31 & 29.2 & 0.645 & 0.422 \\
\hline Fear response to people & 21 & 14.0 & 22 & 20.8 & 2.028 & 0.154 \\
\hline Fear response to objects & 29 & 19.3 & 17 & 16.0 & 0.458 & 0.499 \\
\hline Fear response to situations & 43 & 28.7 & 29 & 27.4 & 0.053 & 0.819 \\
\hline Aggression toward animals & 19 & 12.7 & 22 & 20.8 & 2.786 & 0.095 \\
\hline Pica & 27 & 18.0 & 15 & 14.2 & 0.671 & 0.413 \\
\hline Urine spraying & 25 & 16.7 & 12 & 11.3 & 1.436 & 0.231 \\
\hline Urination outside the litter tray & 21 & 14.0 & 13 & 12.3 & 0.162 & 0.893 \\
\hline Aggression toward people & 1 & 0.7 & 4 & 3.8 & $\mathrm{n} / \mathrm{a}^{*}$ & $\mathrm{n} / \mathrm{a}^{*}$ \\
\hline
\end{tabular}

Bonferroni-corrected alpha-level: 0.003 .

\section{Cat demographics}

Remarkably, information was collected for only 22 Bengal cats from the Wallonia region, and the number of F1-F4 Bengal cats was low in comparison with the other regions. A possible explanation for this is the mandatory registration of all Bengal cats in Wallonia, risking prosecution, and the more complicated registration of the early generation Bengal cats in this region. There may be a fear of

\section{Table 8}

Health problems associated with the Bengal breed and number and percentage of Bengal cats that experience these conditions in Flanders, Wallonia, and the Netherlands according to their owners $(\mathrm{N}=249)$

\begin{tabular}{lcc}
\hline Health problem & \multicolumn{2}{l}{$\begin{array}{l}\text { Bengal cats that have this } \\
\text { condition }\end{array}$} \\
\cline { 2 - 3 } \cline { 2 - 3 } & $\mathrm{n}$ & $\%$ \\
\hline Overweight & 12 & 4.9 \\
Flat-chested kitten syndrome & 3 & 1.2 \\
Patella luxation & 2 & 0.8 \\
Hypertrophic cardiomyopathy & 2 & 0.8 \\
Hip dysplasia & 2 & 0.8 \\
Blindness during the first year & 1 & 0.4 \\
Progressive retinal atrophy & 1 & 0.4 \\
Fertility problems & 1 & 0.4 \\
Distal neuropathy & 0 & 0 \\
Other & 30 & 12.0 \\
\hline
\end{tabular}

seizure of the animal in case of noncompliance ("Bien-être animal Bengal cat," Wallonie Service Public.). Although the anonymity of the questionnaire responses was emphasized in the invitation, the participation in Wallonia remained low, making it difficult to establish a meaningful comparison between regions.

\section{Cat living environment}

More than half of the Bengal cats did not have outdoor access. This finding agrees with Brander and Warren (2016), who observed that although Bengal cats have a preference to be outdoors, they are often kept indoors. In this study, the high percentage of indoor cats could have been partially explained by the high percentage of intact cats, as it has been suggested that intact cats are often kept indoors to avoid undesirable pregnancies (Scherk, 2016). However, the difference between the number of neutered and intact cats that

Table 7

Information about other species that the cat is in contact with and whether there are conflicts with those animals

\begin{tabular}{|c|c|c|c|c|c|}
\hline Category & $\mathrm{n}$ & $\%$ & Sub-category & $\mathrm{n}$ & $\%$ \\
\hline \multirow[t]{4}{*}{ In contact with other Bengal cats } & 46 & 18.0 & Aggressivity & 3 & $6.5 \%$ \\
\hline & & & Fear & 2 & $4.4 \%$ \\
\hline & & & Aggressivity and Fear & 0 & $0.0 \%$ \\
\hline & & & No Conflicts & 41 & $89.1 \%$ \\
\hline \multirow[t]{4}{*}{ In contact with non-Bengal cats } & 45 & 17.6 & Aggressivity & 4 & $8.9 \%$ \\
\hline & & & Fear & 2 & $4.4 \%$ \\
\hline & & & Aggressivity and Fear & 2 & $4.4 \%$ \\
\hline & & & No Conflicts & 37 & $82.3 \%$ \\
\hline \multirow[t]{4}{*}{ In contact with Bengal cats and non-Bengal cats } & 25 & 9.8 & Aggressivity & 4 & $16.0 \%$ \\
\hline & & & Fear & 2 & $8.0 \%$ \\
\hline & & & Aggressivity and Fear & 2 & $8.0 \%$ \\
\hline & & & No Conflicts & 17 & $68.0 \%$ \\
\hline \multirow[t]{4}{*}{ In contact with dogs } & $12^{\mathrm{a}}$ & 4.6 & Aggressivity & 0 & $0.0 \%$ \\
\hline & & & Fear & 0 & $0.0 \%$ \\
\hline & & & Aggressivity and Fear & 0 & $0.0 \%$ \\
\hline & & & No Conflicts & $11^{\mathrm{a}}$ & $100.0 \%$ \\
\hline \multirow[t]{4}{*}{ In contact with dogs and cats } & 73 & 28.5 & Aggressivity & 12 & $16.5 \%$ \\
\hline & & & Fear & 5 & $6.8 \%$ \\
\hline & & & Aggressivity and Fear & 0 & $0.0 \%$ \\
\hline & & & No Conflicts & 56 & $76.7 \%$ \\
\hline \multirow[t]{4}{*}{ Living with other species only (rabbits, reptiles) } & 5 & 2.0 & Aggressivity & 0 & $0.0 \%$ \\
\hline & & & Fear & 1 & $20.0 \%$ \\
\hline & & & Aggressivity and Fear & 0 & $0.0 \%$ \\
\hline & & & No Conflicts & 4 & $80.0 \%$ \\
\hline \multirow[t]{4}{*}{ Only regular contact with strange cats } & 17 & 6.6 & Aggressivity & 6 & $35.3 \%$ \\
\hline & & & Fear & 0 & $0.0 \%$ \\
\hline & & & Aggressivity and Fear & 1 & $5.9 \%$ \\
\hline & & & No Conflicts & 10 & $58.8 \%$ \\
\hline No contact with other animals & 33 & 12.9 & $\mathrm{n} / \mathrm{a}$ & $\mathrm{n} / \mathrm{a}$ & $\mathrm{n} / \mathrm{a}$ \\
\hline
\end{tabular}

\footnotetext{
a The extra information regarding one of the cats that was in contact with dogs was not provided.
} 
were kept indoors was small. An indoor-only life is a factor that has been described to contribute to the occurrence of some behavioral problems such as inappropriate elimination or pica (Amat et al., 2009; Porters et al., 2014) but also to decrease the occurrence of others, for example, intra-cat aggressivity (Levine et al., 2005). In our study, there were no significant differences in the behavior of cats with and without outdoor access. Nevertheless, it has been reported that indoor cats are more likely to be relinquished (Stella and Croney, 2016), and not having outdoor access could potentially be a particularly important welfare issue for Bengal cats, even if not perceived by the owner. Indoor cats, in general, need extra stimulation to avoid having their welfare compromised (International Cat Care, 2019) and Bengal cats are also often described as active cats that need extra stimulation and tend to display predatory behaviors more often than other breeds (Wilhelmy et al., 2016). Proper enrichment and toys designed to elicit hunting behaviors should be recommended to owners of Bengal cats, especially those without outdoor access (Brander and Waran, 2016). In this study, most cats had toys available, although not all of them were interested in them.

Most of the Bengal cats lived or had contact with other animals of the same or a different species, and one in four displayed aggressive behaviors, fear behaviors, or both. In addition, one in four Bengal cats that lived with both Bengal cats and non-Bengal cats displayed either aggressive or fearful behaviors toward the other cats. This is not uncommon in multi-cat households (Bradshaw et al., 2012b), but the percentage is higher than previously reported (Levine et al., 2005). However, it is difficult to associate this with the breed since aggressivity can depend on several factors. For instance, Levine et al, (2005a) described that the chances of aggression between cats in the same household was associated with outdoor access, outdoor access being associated with a higher prevalence of intra-cat aggressivity. In this study, Bengal cats with outdoor access presented slightly more intra-cat aggressivity than the indoors-only cats, but the difference was not significant. Nevertheless, despite a high percentage of cats in this study not having outdoor access, the percentage of aggression was still high and could be an indication of other factors influencing this percentage. For example, it has been suggested that intact females (Finkler and Terkel, 2010) and intact males (Beaver, 2004; Overall et al., 2005) tend to display more aggressive behaviors toward other cats. The high number of non-neutered cats in our population could therefore explain the frequency of aggression, but a potential higher predisposition of Bengal cats to display aggression toward other cats cannot be dismissed based on our results.

Conflicts with strange cats were also frequently described in the questionnaire. Several authors (Hart et al., 2013; Wassink-van der Schot et al., 2016) described the behavior as typical of the Bengal breed, but again, aggressive behavior can have different possible causes, and it is not necessarily a breed-related trait (Levine et al., 2005; Overall et al., 2005).

Half of the cats spent long periods of time alone, and approximately one in ten of those cats displayed behaviors in the absence of the owners that could indicate the presence of a separationrelated problem. This percentage is similar to those previously reported (de Souza Machado et al., 2020) and does not seem to indicate a more severe problem affecting Bengal cats. Nevertheless, a much more in-depth assessment would be necessary to identify a separation-related problem.

\section{Behavior, problematic behavior, and behavior problems}

\section{Behaviors frequently considered problematic}

The percentage of behaviors considered problematic by the owners in this study was in line with what is reported in the literature. In the study by Strickler and Shull (2014), 61\% of the participant cat owners reported at least one from a list of six potentially undesirable behaviors, although they did not indicate whether they did consider them undesirable.

Almost all Bengal cats in this survey displayed behaviors described as typical for the breed, such as frequently vocalizing, playing with water and behaviors that, despite being common to most breeds, are considered particularly important for Bengal cats, for example, climbing and hunting (Braastad et al., 2016; Salonen et al., 2019). Out of all these behaviors, vocalization was most frequently problematic to the owners. This fact has also been previously mentioned in other studies such as Wassink-van der Schot et al. (2016) and Braastad et al. (2016).

In our study, the behaviors most frequently defined by respondents as problematic or inconvenient were inappropriate elimination, spraying, and aggression toward people. These findings are similar to the ones described in Porters et al. (2014) and Moons et al. (2018), who also found that cat owners are particularly displeased with those behaviors. However, the number of Bengal cats from our study that displayed these behaviors was low compared with other studies. For instance, the two most frequent problematic behaviors reported by Strickler and Shull (2014) were also aggression to the owners (36\%) and inappropriate elimination (24\%), but the occurrence was considerably higher than in our study ( $2 \%$ and $13.3 \%$ respectively). Interspecific aggressivity has also been described to be more common in other studies' populations such as Cannas et al. (2018) (14.9\%) and in Berteselli et al. (2008a) (53\%). The percentage of cats presenting inappropriate elimination was also higher in those studies, with $48 \%$ reported by Berteselli et al. (2008b) and $51.2 \%$ by Cannas et al.(2018).

Other potentially problematic behaviors, such as destructive behaviors, pica, and fear and aggression toward other animals, were more frequently displayed but less often perceived as problematic by the respondents. These are behaviors that have also been associated with the Bengal breed (Salonen et al., 2019).

Pica was the most frequent behavior of those considered problematic by the respondents, with a prevalence higher than some studies (Bamberger and Houpt, 2006) but lower than others (Bradshaw et al., 1997; Demontigny-Bédard et al., 2016). In the case of Bradshaw et al.'s study, the population consisted mainly of cats belonging to Asiatic breeds, which are believed to be especially predisposed to this type of behavior. In addition to being associated with some breeds, pica has also being linked with other factors such as early weaning (Bradshaw et al., 1997), stress (Amat et al., 2016), indoor confinement (Schubnel and Arpaillange, 2008), and frustrated hunting behaviors (Neville, 1996). These two last factors are probably related, and they are present in the population of this study. Since hunting seems to be an important behavior for Bengal cats, this factor, together with the high number of indoor-only cats, could influence the percentage of pica. In this study, pica was indeed more often displayed by indoor-only cats, but the difference was not significant. However, in a more recent study by Demontigny-Bédard et al (2016), having outdoor access was significantly associated with the presence of pica. Since the causes of this behavior are not clear, it is difficult to draw any conclusions.

Destructive behavior was another of the more frequent behaviors considered problematic by half of the owners. This behavior has been frequently associated with the Bengal breed, particularly when they do not receive enough attention or do not have enough enrichment available (Brander and Waran, 2016). In this population, most cats had permanent access to toys, but the daily amount of interaction with the owners was very variable. In addition, since most of the cats were living indoors, it is likely that they were less stimulated, and therefore, more prone to display destructive behaviors.

It should be noted that despite of not being considered problematic by many owners, these behaviors can still be indicative of 
behavior and/or welfare problems. However, an extensive assessment of each individual case would be necessary to understand the causes behind them.

Last, analysis of the data did not show significant differences in the behaviors displayed by cats from F1-F4 and cats from F5 or later. This conflicts with the extended belief that earlier generations tend to exacerbate some behaviors such as urine spraying or aggressivity (Belyaev, 1979). And would suggest that the fact that many owners (especially in Flanders and the Netherlands) were unaware of which generation their cat belongs to would not have an impact in their expectations and the cats' chances of relinquishment.

\section{Behavioral problems}

Behavioral problems are considered one of the main reasons for relinquishment (Stella and Croney, 2016). Only 7 Bengal cats from this survey had been diagnosed with behavioral problems, although no information was collected about who had performed the examination and diagnosis, and one in ten of the respondents suspected a behavioral problem. The presence of behavioral problems was low compared with other epidemiological studies, particularly considering that most of the cats did not have outdoor access. For example, in their study, Finka et al., (2019) reported that $20 \%$ of the respondents from a total of 3165 cat owners indicated that their cats presented a behavioral problem. However, almost half of the cats displayed at least one behavior that was considered problematic by the owners, a percentage more in line with those reported previously (Heidenberger, 1997). That could indicate that despite of being frequently considered annoying by the owners, most behaviors were not given enough importance or were not severe enough to be considered a behavior problem.

\section{Health problems}

Most of the cats in the study did not present any health issues, according to the respondents.

International Cat Care suggested multiple diseases as being more common in the Bengal breed (International Cat Care, 2017). From those diseases, the most frequently described problem was overweight, which could be linked with the fact that a high percentage of these cats lived indoors, one of the risk factors for overweight in cats in general (Kaufman et al., 2013; Rowe et al., 2015). Nevertheless, the percentage of overweight cats in this study is notably lower than the prevalence of cat overweight in the developed world as reported in different studies, which varies from $11.5 \%$ to $63 \%$ (Wall et al., 2019).

Decreased fertility, which, according to Lyons (2015), can persist up to the 29th generation of the breed, was not described. However, many of the Bengal cats in this study had been neutered, and it is not known whether they could have produced litters before the surgery.

Regarding the progressive retinal atrophy, the prevalence in this study is consistent with previous reports (Ofri et al., 2015). A DNAtest exists for this condition, but its use is not mandatory for Bengal breeders in Belgium and The Netherlands. Phenotypical screening by an ophthalmologist is recommended, but there is no legal obligation to do this (Belgian Cat Club, 1999). Nevertheless, some breeders could be using this screening to select cats for reproduction, thereby decreasing the chances of progressive retinal atrophy presentation.

The fact that the population was relatively young could also explain the lower presence of some of these diseases. Some of them could be present subclinically, and therefore, not yet observed by the owner (Bourguet et al., 2018). However, this is not always the case since some of the conditions such as polyneuropathy (Bensfield et al., 2011), the flat-chested kitten syndrome, or the progressive retinal degeneration (Ofri et al., 2015) usually present an early onset.

\section{Owner expectations}

Very few respondents, according to the results of this survey, have become owners of a Bengal cat without searching for information about the breed in advance. Preacquisition information was mainly obtained through both the Internet and breeders' advice. Internet was the most frequent source of information, which is similar to what has been described for owners of other purebred cats (Plitman et al., 2019). Bengal cats are often described in specialized websites as active, playful, social, and vocal cats. The fact that Bengal owners tend to do some research before acquiring their cats-most of the time using the internet-may indicate that those were personality traits that they considered desirable in their future cats or at least were not opposed to. However, it is important to consider that internet was often the only source of information, and it cannot always be considered as reliable (Oxley et al., 2017). Consequently, the description of the Bengal cat character may be different between respondents.

Interestingly, veterinarians were never mentioned as a source of information by any of the respondents. That could indicate that vets are not seen as a source of medical and behavioral information when people select a pet, and they should make a greater effort to profile themselves in this role. For example, in the UK, the British Veterinary Association (BVA) has recently encouraged veterinarians to offer pre-purchase consultations to advise people that are considering buying animals from brachycephalic breeds to avoid acquiring animals with potentially compromised welfare (Atkin, 2018). Similarly, veterinarians could help manage expectations of future cat owners by offering information about potential breedrelated issues and breed particularities.

Regarding the reasons why the respondents opted for a Bengal cat and not a different breed, both character and appearance were ultimately the most important factors. The character was the most important single factor, with a percentage higher than appearance alone. This contrasts with the findings in Plitman et al. (2019), where the three groups of cat owners (brachycephalic with pedigree, nonbrachycephalic with pedigree, and cats without pedigree) gave more importance to their cats' appearance that to their behavior. It had also been previously described that owners choose their cats, usually based on their appearance (Onodera et al., 2014). Despite of this, Neidhart and Boyd (2002) found that personality was the first reason linked with post-adoption owner satisfaction (Delgado et al., 2012).

The owner's expectations and knowledge of the specie's typical behavior (Scarlett et al., 1999; Stella and Croney, 2016) are also considered as factors that influence the probabilities of relinquishment. In this study, most respondents searched for information about the characteristics of the Bengal breed before acquiring a cat and seemed to value the character of the breed in addition to its physical appearance. This could explain that most owners did not find behaviors considered typical of the breed problematic, and the most frequent behaviors that were considered problematic were behaviors also common in other breeds. This fact may have a positive repercussion on how well the owner's expectations match reality, and therefore, how satisfied they are with their purchase. A high level of owner satisfaction should lead to a lower number of relinquished cats (Casey et al., 2009).

\section{Conclusions}

The results of this questionnaire did not reveal any strong indications of severe breed-related behavioral or health problems in 
the Bengal cats from the perspective of the owners and therefore does not seem to indicate a probability of relinquishment higher than other breeds. Most of the respondents searched for information before purchasing the cats and decided to acquire them not only for their appearance but also because of their character. This could explain why most of the owners were not disturbed by the behaviors typical of the breed, such as vocalization, climbing, playing with water, with the sole exception of aggression toward humans. Some behaviors that may be indicative of a welfare issue and have been previously associated with Bengal cats, such as destruction and pica, were also present, but they were not perceived as a problem by the owners. As described in the literature, urinating outside the litter box and spraying were the behaviors that made owners most unhappy, but these behaviors were less frequent than in other studies regarding non-Bengal populations. There were no differences in behavior between early and later generations of Bengal cats and between cats with and without outdoor access. None of the health issues most associated with the breed were common. The study did not show issues that affect the suitability of Bengal cats, specifically, as pets from the owners' point of view, although the respondents indicated that several undesired behaviors were present in this population and the cats that presented those behaviors could still be at risk of relinquishment due to the owner's dissatisfaction. In addition, since some behaviors not considered problematic by the owners could be signaling welfare issues, further and more in-depth research is recommended to be able to draw conclusions about the suitability of Bengal cat as a pet from the cat's own point of view.

\section{Acknowledgments}

The authors wish to thank the owners of the Bengal cats who took the time and effort to respond to our survey. They also thank the anonymous reviewers for their helpful comments.

Authorship statement: The idea for the paper was conceived by H. Vervaecke and C.P.H. Moons. The experiments were performed by J. Rosseau. The data were analyzed by A. Martos Martinez-Caja and J. Rosseau. The paper was written by A. Martos MartinezCaja, J. Rosseau, H. Vervaecke and C.P.H. Moons.

\section{Ethical considerations}

This research did not involve the use of live animals, nor did it involve the acquisition of identifiable private information about human subjects.

\section{Conflict of interest}

The authors have no conflict of interest to declare.

\section{Supplementary data}

Supplementary data to this article can be found online at https:// doi.org/10.1016/j.jveb.2020.10.007.

\section{References}

Amat, M., Camps, T., Manteca, X., 2016. Stress in owned cats: behavioural changes and welfare implications. J. Feline Med. Surg. 18, 577-586.

Amat, M., de la Torre, J.L.R., Fatjó, J., Mariotti, V.M., Van Wijk, S., Manteca, X., 2009. Potential risk factors associated with feline behaviour problems. Appl. Anim. Behav. Sci. 121, 134-139.

Anonymous, 2017. Bengal Genetics [WWW Document]. https://www.bengalgenetics.com/. Accessed November 18, 2019.

Atkin, H., 2018. Take action on brachycephalic dogs. Vet. Rec. 182, 31.
Bamberger, M., Houpt, K.A., 2006. Signalment factors, comorbidity, and trends in behavior diagnoses in cats: 736 cases (1991-2001). J. Am. Vet. Med. Assoc. 229, 1602-1606.

Beaver, B.V., 2004. Fractious cats and feline aggression. J. Feline Med. Surg. 6, 12-18. Belgian Cat Club, 1999. [WWW Document]. http://www.belcat.be/nl/kat/health/ index.php. Accessed February 12, 2019.

Belyaev, D.K., 1979. Destabilizing selection as a factor in domestication. J. Hered. 70 301-308.

Bensfield, A.C., Evans, J., Pesayco, J.P., Mizisin, A.P., Shelton, G.D., 2011. Recurrent demyelination and remyelination in 37 young Bengal cats with polyneuropathy. J. Vet. Intern. Med. 25, 882-889.

Berteselli, G., Cannas, S., Michelazzi, M., Volonte, L., Palestrini, C., 2008a. Focus on feline behavioural disorders. Part II: Feline aggression. Vet 22, 27-33.

Berteselli, G., Cannas, S., Michelazzi, M., Volontè, L., Palestrini, C., 2008b. Focus on feline behavioural disorders. Part I: Inappropriate elimination and marking. Vet 22, 21-26.

Big Cat Rescue, 2019. Hybrid Cat Facts, Photos, Videos, Stories [WWW Document]. https://bigcatrescue.org/hybrid-facts/. Accessed May 21, 2019.

Bourguet, A., Chaudieu, G., Briatta, A., Guyonnet, A., Abitbol, M., Chahory, S., 2017. Cataracts in a population of Bengal cats in France. Vet. Ophthalmol. 21 (1), 1018.

Braastad, B.O., Eriksen, S.C.B., Serpell, J.A., 2016. Breed, gender and age variation in behavioural traits in domestic cats (Felis silvestris catus). In: Proceedings of the 50 Th Congress of the International Society for Applied Ethology 12-15 Th July, 2016, Edinburgh, United Kingdom, p. 72.

Bradshaw, J.W.S., Casey, R.A., Brown, L., 2012a. Domestication and Biology. In: The Behaviour of the Domestic Cat. CABI, Oxfordshire, United Kingdom.

Bradshaw, J.W.S., Casey, R.A., Brown, L., 2012b. Undesired Behaviours in the Domestic Cat. In: The Behaviour of the Domestic Cat. CABI, Oxfordshire, United Kingdom.

Bradshaw, J.W.S., Neville, P.F., Sawyer, D., 1997. Factors affecting pica in the domestic cat. Appl. Anim. Behav. Sci. 52, 373-379.

Brander, D., Waran, N., 2016. Welfare issues in companion animal behaviour. In: Appleby, D. (Ed.), The APBC Book of Companion Animal Behaviour. Souvenir Press Ltd, London, UK.

Cameron-Beaumont, C., Lowe, S.E., Bradshaw, J.W.S., 2002. Evidence suggesting preadaptation to domestication throughout the small Felidae. Biol. J. Linn. Soc. $75,361-366$

Cannas, S., Casavecchia, M., Mazzola, S., Palestrini, C., 2018. Caratteristiche dei gatti sottoposti a visite comportamentali : uno studio retrospettivo. Vet 5, 315-320.

Casey, R.A., Vandenbussche, S., Bradshaw, J.W.S., Roberts, M.A., 2009. Reasons for relinquishment and return of domestic cats (felis silvestris catus) to rescue shelters in the UK. Anthrozoos 22, 347-358.

Cutts, L.A., 2008. Walking on the wild side: classification and liability for owners of wild-domestic animal hybrids. San Joaquin Agric. Law Rev. 18.

de Souza Machado, D., Oliveira, P.M.B., Machado, J.C., Ceballos, M.C., Sant’Anna, A.C., 2020. Identification of separation-related problems in domestic cats: A questionnaire survey. PLoS ONE 15 (4), 1-19.

Delgado, M.M., Munera, J.D., Reevy, G.M., 2012. Human perceptions of coat color as an indicator of domestic cat personality. Anthrozoos 25, 427-440.

Demontigny-Bédard, I., Beauchamp, G., Bélanger, M.C., Frank, D., 2016. Characterization of pica and chewing behaviors in privately owned cats: a case-control study. J. Feline Med. Surg. 18, 652-657.

DEWHA (Department of the Environment, Water, Heritage and the Arts, Australia) 2008. Final environmental assessment of the suitability of the import of the Savannah Cat (Domestic Cat x Serval hybrid specimens) into Australia. In: Final Assessment Report dated 24 July 2008, prepared pursuant to the Environment Protection and Biodiversity Counsel.

Finka, L.R., Ward, J., Farnworth, M.J., Mills, D.S., 2019. Owner personality and the wellbeing of their cats share parallels with the parent-child relationship. PLoS One 14, e0211862.

Finkler, H., Terkel, J., 2010. Cortisol levels and aggression in neutered and intact freeroaming female cats living in urban social groups. Physiol. Behav. 99, 343-347.

Gershony, L.C., Penedo, M.C.T., Davis, B.W., Murphy, W.J., Helps, C.R., Lyons, L.A., 2014. Who's behind that mask and cape? the Asian leopard cat's Agouti (ASIP) allele likely affects coat colour phenotype in the Bengal cat breed. Anim. Genet. $45,893-897$.

Hart, B.L., Hart, L.A., Lyons, L.A., 2013. Breed and gender behaviour differences: relation to the ancient history and origin of the domestic cat. In: The Domestic Cat: The Biology of its Behaviour. Cambridge University Press, Cambridge United Kingdom.

Heidenberger, E., 1997. Housing conditions and behavioural problems of indoor cats as assessed by their owners. Appl. Anim. Behav. Sci. 52, 345-364.

International Cat Care, 2017. Bengal [WWW Document]. https://icatcare.org/advice/ cat-breeds/bengal. Accessed November 6, 2019.

International Cat Care, 2019. Indoor-only or outdoor access? | International Cat Care [WWW Document]. https://icatcare.org/indoor-only-or-outdoor-access/. Accessed April 7, 2020.

Kaufman, A.B., Colbert-White, E.N., Burgess, C., 2013. Higher-order semantic structures in an African Grey parrot's vocalizations: evidence from the hyperspace analog to language (HAL) model. Anim. Cogn. 16, 789-801.

Kukekova, A.V., Trut, L.N., Chase, K., Kharlamova, A.V., Johnson, J.L., Temnykh, S.V. Oskina, I.N., Gulevich, R.G., Vladimirova, A.V., Klebanov, S., Shepeleva, D.V., Shikhevich, S.G., Acland, G.M., Lark, K.G., 2011. Mapping loci for fox 
domestication: deconstruction/reconstruction of a behavioral phenotype. Behav. Genet. 41, 593-606.

Levine, E., Perry, P., Scarlett, J., Houpt, K.A., 2005a. Intercat aggression in households following the introduction of a new cat. Appl. Anim. Behav. Sci. 90, $325-336$.

Lyons, L.A., 2015. DNA mutations of the cat. J. Feline Med. Surg. 17, 203-219.

Marder, A., Duxbury, M.M., 2008. Obtaining a Pet: Realistic Expectations. Vet. Clin. North Am. Small Anim. Pract..

Moons, C.P.H., Valcke, A., Verschueren, K., Porters, N., Polis, I., de Rooster, H., 2018. Effect of early-age gonadectomy on behavior in adopted shelter kittens-The sequel. J. Vet. Behav.: Clin. Appl. Res. 26, 43-47.

Neidhart, L., Boyd, R., 2002. Companion animal adoption study. J. Appl. Anim. Welf. Sci. 5, 175-192.

Neville, P.F., 1996. Treatment of fabric-eating disorder in cats. North Am. Vet. Conf.

Ofri, R., Reilly, C.M., Maggs, D.J., Fitzgerald, P.G., Shilo-Benjamini, Y., Good, K.L., Grahn, R.A., Splawski, D.D., Lyons, L.A., 2015b. Characterization of an earlyonset, autosomal recessive, progressive retinal degeneration in bengal cats. Investig. Ophthalmol. Vis. Sci. 56, 5299-5308.

Onodera, N., Uchida, K., Kakuma, Y., 2014. Association between characteristics of cats and satisfaction of owners who adopted cats from an animal hospital in Japan. J. Vet. Med. Sci. 76, 729-733.

Overall, K.L. Rodan, I., Beaver, V., Carney, H., Crowell-Davis, S., Hird, N., Kudrak, S. Wexler-Mitchel, E., 2005. Feline behavior guidelines from the American Association of Feline Practitioners. J. Am. Vet. Med. Assoc. 227, 70-84.

Oxley, J.A., Eastwood, B., Kogan, L.R., 2017. Pet owners and the internet. Companion Anim. 22, 358.

Patronek, G.J., Glickman, L.T., Beck, A.M., McCabe, G.P., Ecker, C.J., 1996. Risk factors for relinquishment of cats to an animal shelter. J. Am. Vet. Med. Ass. 209 (3), $582-588$.

Plitman, L., Černá, P., Farnworth, M.J., Packer, R.M.A., Gunn-Moore, D.A., 2019. Motivation of owners to purchase pedigree cats, with specific focus on the acquisition of brachycephalic cats. Animals 9, 394.

Porters, N., de Rooster, H., Verschueren, K., Polis, I., Moons, C.P.H., 2014. Development of behavior in adopted shelter kittens after gonadectomy performed at an early age or at a traditional age. J. Vet. Behav.: Clin. Appl. Res. 9, 196206.

Rowe, E., Browne, W., Casey, R., Gruffydd-Jones, T., Murray, J., 2015. Risk factors identified for owner-reported feline obesity at around one year of age: Dry diet and indoor lifestyle. Prev. Vet. Med. 121, 273-281.

Salman, M.D., Hutchison, J.M., Ruch-Gallie, R., Kogan, L.R., New Jr, J.C., Kass, P.H., Scarlett, J.M., 2010. Behavioral reasons for relinquishment of dogs and cats to 12 shelters. Appl. Animal Welfare Sci 3 (2), 93-106.
Salonen, M., Vapalahti, K., Tiira, K., Mäki-Tanila, A., Lohi, H., 2019. Breed differences of heritable behaviour traits in cats. Sci. Rep. 9, 7949.

Scarlett, J.M., Salman, M.D., New Jr., J.C., Kass, P.H., 1999. Reasons for relinquishment of companion animals in U.S. animal shelters: Selected health and personal issues. J. Appl. Anim. Welf. Sci. 2, 41-57.

Scherk, M., 2016. Optimizing an indoor lifestyle for cats. Vet. Focus 26, 2-9.

Schubnel, E., Arpaillange, C., 2008. Contribution to the study of indoor cats behavioural problems. Prat. Medicale Chir. Animal Cie. 43, 63-70.

Shore, E.R., 2005. Returning a recently adopted companion animal: Adopters' reasons for and reactions to the failed adoption experience. J. Appl. Anim. Welf. Sci. 8, 187-198.

Stella, J.L., Croney, C.C., 2016. Environmental aspects of domestic cat care and management: implications for cat welfare. Sci. World J., 2016.

Strickler, B.L., Shull, E.A., 2013. An owner survey of toys, activities, and behavior problems in indoor cats. J. Vet. Behav.: Clin. Appl. Res. 9, 207-214.

Ström Holst, B., Frössling, J., 2009. The Swedish breeding cat: population description, infectious diseases and reproductive performance evaluated by a questionnaire. J. Feline Med. Surg. 11, 793-802.

Turner, D.C., Bateson, P.P.G., 2000. The Domestic Cat: The Biology of its Behaviour Cambridge University Press, Cambridge, United Kingdom.

Vapalahti, K., Virtala, A.-M., Joensuu, T.A., Tiira, K., Tähtinen, J., Lohi, H., 2016. Health and Behavioral Survey of over 8000 Finnish Cats. Front. Vet. Sci. 3, 70.

Vervaecke, H., Janssens, S., Buys, N., Van Impe, I., 2016. Hybride Katten in Vlaanderen. https://dierenwelzijn.vlaanderen.be/sites/default/files/atoms/files/ Hybride\%20katten\%20in\%20Vlaanderen\%20-\%20Advies\%20\%282017\%29.pdf. Accessed May 20, 2019.

Vigne, J.D., Evin, A., Cucchi, T., Dai, L., Yu, C., Hu, S., Soulages, N., Wang, W., Sun, Z. Gao, J., Dobney, K., Yuan, J., 2016. Earliest "domestic" cats in China identified as leopard cat (Prionailurus bengalensis). PLoS One 11, e0147295.

Wall, M., Cave, N.J., Vallee, E., 2019. Owner and cat-related risk factors for feline overweight or obesity. Front. Vet. Sci. 6, 1-13.

Wassink-van der Schot, A.A., Day, C., Morton, J.M., Rand, J., Phillips, C.J.C., 2016. Risk factors for behavior problems in cats presented to an Australian companion animal behavior clinic. J. Vet. Behav.: Clin. Appl. Res. 14, 34-40.

Wild Cat Sanctuary, 2012. What is a hybrid wild cat and do they make good pets? [WWW Document]. https://www.wildcatsanctuary.org/education/species/ hybrid-domestic/what-is-a-hybrid-domestic/. Accessed May 21, 2019.

Wilhelmy, J., Serpell, J., Brown, D., Siracusa, C., 2016. Behavioral associations with breed, coat type, and eye color in single-breed cats. J. Vet. Behav.: Clin Appl. Res. 13, 80-87.

Yeates, J., Yates, D., 2017. Editorial: Staying in or going out? the dilemma for cat welfare. Vet. Rec. 180, 193-194. 